\title{
Numerical modelling and fragility assessment of typical freestanding building contents
}

\author{
C. Petrone ${ }^{1}$ (I) $\cdot$ L. Di Sarno ${ }^{2}$ G. Magliulo ${ }^{3}$ E. Cosenza G.4 $^{3,4}$
}

Received: 15 June 2016/ Accepted: 13 October 2016/Published online: 25 October 2016

(C) The Author(s) 2016. This article is published with open access at Springerlink.com

\begin{abstract}
The paper assesses the adequacy of existing numerical models in predicting the seismic response of freestanding nonstructural components that exhibit rocking-dominated behavior. Based on a previous experimental test program on hospital building contents carried out by the authors, the study focuses on two different modelling techniques: (a) finite element method (FEM) and (b) rigid block model. The ability to predict the response of two hospital cabinets tested in the laboratory is verified by comparing the numerical response with the experimental one. The applicability and limitations of each modelling technique are also discussed. The outcomes of the present study show that both the adopted modeling techniques can provide a reliable prediction of the occurrence of rocking mechanism in hospital cabinets. Rigid block model can also predict the occurrence of the overturning, whereas FEM model can provide a prediction of the acceleration distribution at different locations of the cabinets, e.g. at different shelf levels. The efficiency of different intensity measures in predicting the damage states in rigid block is estimated. Comprehensive incremental dynamic analyses on different rigid blocks highlight that dimensionless intensity measure $P G A /(g \operatorname{tg} \alpha)$ is the most efficient intensity measure to predict rocking and overturning in small rigid blocks, whereas $p P G V /(g \operatorname{tg} \alpha)$ is the most effective for large rigid blocks. Such intensity measures also allow generalizing the results to different rigid blocks, through the definition of a fragility approach.
\end{abstract}

Keywords Nonstructural components · Hospital building contents - Seismic performance FEM model $\cdot$ Rigid block $\cdot$ Seismic fragility

\section{Petrone}

c.petrone@ucl.ac.uk

1 Department of Civil, Environmental and Geomatic Engineering, University College London, Chadwick Building, Gower Street, WC1E 6BT London, UK

2 Department of Engineering, University of Sannio, Piazza Roma 21, 82100 Benevento, Italy

3 Department of Structures for Engineering and Architecture, University of Naples Federico II, Via Claudio 21, 80125 Naples, Italy

4 Construction Technologies Institute ITC-CNR, Via Claudio 21, 80125 Naples, Italy 


\section{List of symbols}

$\begin{array}{ll}a_{g} & \text { Ground acceleration } \\ A S I & \text { Acceleration Spectral Intensity (Table 4) } \\ b & \text { Cabinet semi-width (Fig. 9) } \\ C A V & \text { Cumulative absolute velocity (Table 4) } \\ e & \text { Coefficient of restitution (Eq. 2) } \\ g & \text { Acceleration of gravity } \\ h & \text { Cabinet semi-height (Fig. 9) } \\ H I & \text { Housner intensity (Table 4) } \\ I_{A} & \text { Arias intensity (Table 4) } \\ I M & \text { Intensity measure } \\ I M_{4} & \text { Normalized acceleration intensity measure (Table 4) } \\ I M_{5} & \text { Normalized velocity intensity measure (Table 4) } \\ I M_{6} & \text { Normalized velocity intensity measure (Table 4) } \\ I M_{F a j f a r} & \text { Fajfar intensity measure (Table 4) } \\ p & \text { Rigid block frequency parameter (Fig. 9) } \\ P F A & \text { Peak floor acceleration } \\ P G V & \text { Peak ground velocity } \\ R & \text { Rigid block diagonal semi-dimension (Fig. 9) } \\ S_{v} & \text { Pseudo-spectral velocity } \\ S_{a} & \text { Pseudo-spectral acceleration } \\ t_{d} & \text { Earthquake significant duration } \\ T_{m} & \text { Earthquake mean period } \\ T & \text { Structural period } \\ x_{m} & \text { Median value of the lognormal probability distribution } \\ \alpha & \text { Critical angle of the block (Fig. 9) } \\ \beta & \text { Standard deviation of the lognormal probability distribution } \\ \xi & \text { Damping ratio } \\ \theta & \text { Rigid block rotation } \\ \omega_{m} & \text { Earthquake mean angular frequency } \\ & \\ & \end{array}$

\section{Introduction}

One of the focuses of the modern earthquake engineering research is the response analysis, design and assessment of nonstructural components. Such research is motivated by: (a) the threat to life-safety that the collapse of nonstructural components can cause; (b) the attitude of these components in exhibiting damage (and the consequent evacuation of buildings) even for low-intensity earthquakes; (c) the enormous economic loss caused by their damage. The latter motivations are of paramount importance for critical facilities, such as hospital buildings and health care facilities, whose performance is essential in the aftermath of moderate-to-high magnitude earthquake ground motions.

Health care facilities may undergo severe and widespread damage that impairs the functionality of the system when they are stricken by an earthquake. Such detrimental response is emphasized for the hospital buildings designed either primarily for gravity loads or without employing base isolation/supplemental damping systems. Moreover such buildings need to warrant functionality especially in the aftermath of moderate-to-severe earthquake ground motions. Recent surveys carried out in the aftermath of major world- 
wide earthquakes, e.g. (Di Sarno et al. 2013; Jacques et al. 2014; Masi et al. 2014) among others, have shown that the overturning of cabinets, containing medical files with patient details, is a typical non-structural component damage.

In the last three decades thorough governmental actions, aiming at ensuring the life safety and collapse prevention of acute healthcare facilities, have been promoted. For example, in California, in addition to safety standards it is enforced that, by 2030, hospitals should also meet performance levels meant to ensure that they are capable of providing services to public after an earthquake or any other disaster. Numerous initiatives have also been promoted world-wide by the World Health Organization (WHO) and the United Nation International Strategy for Disaster Reduction (UNISDR), e.g. the global campaign "Hospital Safe From Disasters" [World Health Organization (WHO) 2008]. However, designing for resilient hospitals remains a challenging task; it needs an interdisciplinary approach encompassing both the physical, i.e. structure, nonstructural components and building contents, and non-physical components, i.e. procedures, organization and functionality, of a hospital system (Bruneau et al. 2003). Adequate performance criteria and robust but simple assessment methods should be implemented in seismic codes of practice and guidelines. To date, there is a lack of comprehensive theoretical and experimental results dealing with the performance evaluation of the building contents for health care facilities. The earthquake response of such contents is not straightforward because of the complexity and variety of connections and functioning. So far, while few experimental tests have been carried out on buildings equipped with nonstructural components as well as hospital building contents (e.g. Chen et al. 2015; Kuo et al. 2011; Pantoli et al. 2015; Shi et al. 2014), the modelling of hospital building contents is not extensively investigated in literature. Indeed, while the features of several nonstructural components typically require the use of experimental methods, nonstructural component testing tends to be expensive and time-consuming. Therefore the need to define numerical models for the prediction of hospital building content performance is claimed. Some models for sliding-dominated components were investigated in past research studies (Konstantinidis and Makris 2009; Konstantinidis and Nikfar 2015; Lin et al. 2015); the absence of numerical models for rocking-dominated hospital building contents is, however, clearly denoted. The aim of the present research study is to provide simple tools to both researchers and practitioners for the assessment of the seismic performance of hospital building contents.

The present work is aimed to assess the adequacy of existing numerical modeling approaches in predicting the seismic response of freestanding nonstructural components with rocking-dominated response to support future modelling exercises of these components. Towards this aim, the results of an experimental study carried out for a full scale three-dimensional model of a consultation room are employed to validate numerical models. Two different modeling techniques are selected to analyze the seismic performance of two freestanding cabinets included in the consultation room: (a) finite element method (FEM) and (b) rigid block modeling. Reference experimental tests are first presented in Sect. 2; then the paper addresses two main goals: the validation of the two considered numerical modelling approaches in Sects. 3 and 4, and their fragility assessment in Sect. 5. In Sect. 3 FEM modeling technique, typically employed for structural analysis, is adopted to model freestanding cabinets before rocking occurs. Rigid block modeling, which was extensively investigated and applied to different structural engineering topics (Dimitrakopoulos and DeJong 2012; Dimitrakopoulos and Paraskeva 2015; Psycharis et al. 2013), is employed in Sect. 4 to assess the behavior of cabinets in case rocking mechanism occurs. The validation of the numerical model stimulates a fragility 
analysis of rigid blocks characterized by different geometric features (Sect. 5). The efficiency of several intensity measures is estimated and an attempt to generalize the results, proposing a unique fragility curve for different rigid blocks, is included.

\section{Experimental tests}

Numerical models developed in the following sections are validated against the outcomes of a comprehensive experimental campaign on hospital building contents (Cosenza et al. 2014). Shake table tests were carried out on a typical hospital examination room (Fig. 1). The behavior of two full scale building contents used for the examination room was investigated in this study (Fig. 1b):

- a hospital medicine cabinet made of cold formed steel with dimension $75 \times 38 \times 165 \mathrm{~cm}$, having double moving glass doors with locker and four shelves;

- a hospital medicine cabinet made of cold formed steel with dimension $53 \times 36 \times 139 \mathrm{~cm}$, having single moving glass door with locker and four shelves.

The mass of the two (empty) cabinets was respectively $20 \mathrm{~kg}$ for the double-window cabinet and $15 \mathrm{~kg}$ for the single-window cabinet. Contents were also included within the cabinets. Different mass distributions, obtained by either bowls filled with sand or realistic glass contents, were also considered for both the double- and single-window cabinets.

Three different test campaigns, named test groups, were considered hereafter. In test group 100, $6 \mathrm{~kg}$ mass was added to each shelf of the double-window cabinet, whereas $4 \mathrm{~kg}$ mass was added to each shelf of the single-window cabinet. The total added mass amount, which is $120 \%$ and $107 \%$ of the cabinet mass respectively, is representative of the mass of typical contents inserted in such a cabinet. In test group 200 the dynamic behavior of the cabinets with a decreasing mass distribution along the height was investigated. From the base to the top, 6, 4, 4 and $2 \mathrm{~kg}$ masses (totally $80 \%$ of cabinet mass) were placed on the four shelves of the double-window cabinet, while 4, 2, 2 and $0 \mathrm{~kg}$ masses (totally $53 \%$ of
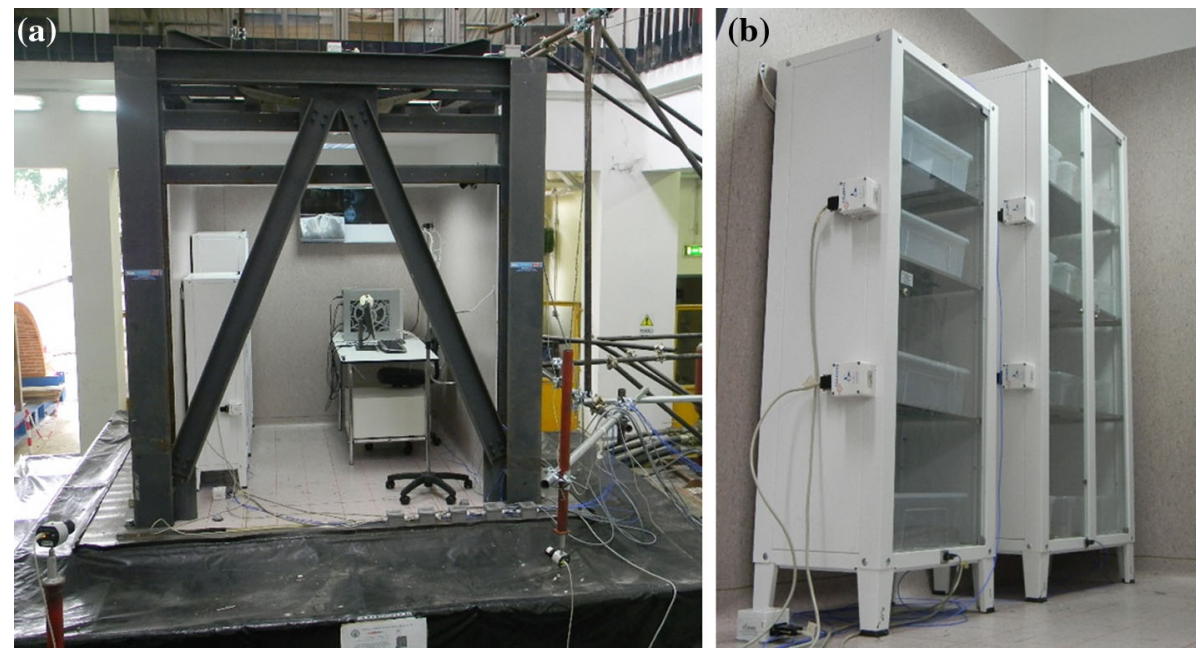

Fig. 1 a Global view on the tested hospital examination room and $\mathbf{b}$ close-up view on the two cabinets 
cabinet mass) were placed on the four shelves of the single-window cabinet. In test group 300 , typical glass contents, equally placed on the different shelves of each cabinet, were tested. Glass bottles with different dimensions, i.e. 100, 250 and $500 \mathrm{ml}$, were included in the double-window cabinet, whereas 250 and $100 \mathrm{ml}$ glass beakers, flasks and test tubes were placed in the single-window cabinet. Further details on the experimental test program are included in Cosenza et al. (2014).

The shake table tests were performed according to the testing protocol included in AC 156 (International Conference of Building Officials (ICBO) 2000), which is applied to acceleration-sensitive nonstructural elements. Several tests were performed at increasing intensity in order to assess the acceleration threshold value required to attain a given damage in the components. For instance, ten shake table tests were performed for test group 100 , namely tests from 101 to 110 , corresponding to peak table accelerations which range from 0.12 to $1.27 \mathrm{~g}$ (Table 1$)$. The latter accelerations can be considered typical peak floor accelerations (PFAs) recorded at mid-height of multi-story hospital buildings located in moderate-to-high seismicity. Unidirectional motions were applied to shake the cabinets along their transversal direction, i.e. along their shorter sides (Fig. 2). High quality digital accelerometers were used to monitor the response of the hospital building contents. Four accelerometers were positioned at the base, i.e. at the lowest shelf level, and at the top of the front side of each cabinet; one accelerometer recorded the acceleration at the shake table level. The tested cabinets did not show any sliding mechanism, due to their slenderness and the large friction ensured at their base. It should be considered that other cabinets might show a significant sliding behavior, which can be investigated as in previous literature studies (Lin et al. 2015; Lopez Garcia and Soong 2003).

\section{Model for pre-rocking behavior}

This section deals with the investigation of the dynamic behavior of hospital cabinets when they do not exhibit any rocking mechanism, i.e. for pre-rocking behavior. The validation of a FEM model for the dynamic performance of cabinets is presented in Sect. 3.1. Its ability to reproduce horizontal accelerations in the cabinets is also discussed. The distribution of the horizontal acceleration along the height of the cabinet during the pre-rocking phase is finally presented in Sect. 3.2.

Table 1 Recorded peak floor acceleration for each test of the testing protocol

\begin{tabular}{|c|c|c|c|c|c|}
\hline \multicolumn{2}{|c|}{ Test group 100} & \multicolumn{2}{|c|}{ Test group 200} & \multicolumn{2}{|c|}{ Test group 300} \\
\hline Test ID & PFA (g) & Test ID & PFA (g) & Test ID & PFA $(g)$ \\
\hline 101 & 0.13 & & & 301 & 0.12 \\
\hline 102 & 0.24 & & & 302 & 0.23 \\
\hline 103 & 0.37 & 203 & 0.36 & 303 & 0.35 \\
\hline 104 & 0.49 & 204 & 0.48 & 304 & 0.48 \\
\hline 105 & 0.61 & 205 & 0.60 & 305 & 0.60 \\
\hline 106 & 0.74 & 206 & 0.72 & 306 & 0.73 \\
\hline 107 & 0.89 & 207 & 0.85 & 307 & 0.84 \\
\hline 108 & 0.98 & 208 & 0.98 & 308 & 0.98 \\
\hline 109 & 1.13 & 209 & 1.13 & 309 & 1.12 \\
\hline 110 & 1.25 & 210 & 1.26 & 310 & 1.27 \\
\hline
\end{tabular}



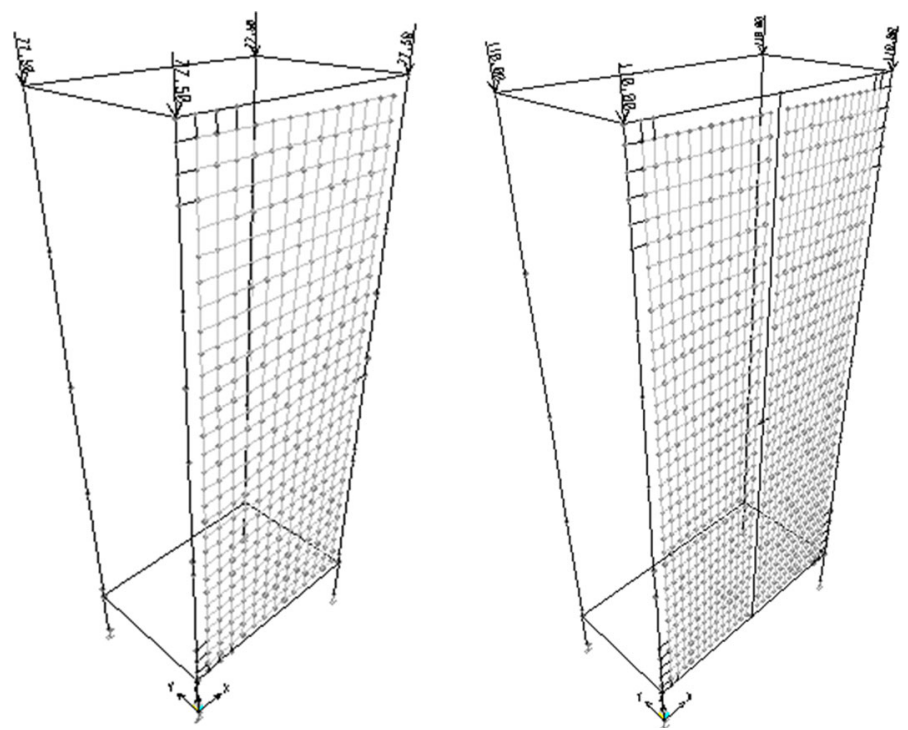

Fig. 2 Finite element model of the tested cabinets for test group 100 (applied forces are in N)

\subsection{Finite element models}

Low-amplitude random vibrations were utilized to validate the numerical FEM model of the tested cabinets (Di Sarno et al. 2015a, b), developed in SAP 2000 (CSI Computer and Structures Inc. 2004). The numerical model provided a fairly good matching in terms of natural frequencies of the sample components. In this study, the numerical-to-experimental comparison is extended to the shaking table tests performed according to AC156. The reliability of the selected model to reproduce the recorded accelerations, e.g. top cabinet accelerations, when subjected to a predefined ground motion is assessed. Such a model would allow the estimation of the acceleration demand at each shelf of the cabinet, which excites the contents; moreover, it could be also used to check the likely occurrence of any rocking mechanism, as shown in the following.

Each cabinet consists of four steel vertical columns connected each other by steel elements. The steel vertical columns are characterized by $0.1 \mathrm{~cm}$ thick "L" cross-section. They are connected by two steel horizontal plates, at the top of the cabinet and at $17 \mathrm{~cm}$ height from their base. Three of the four vertical bays are infilled with $0.1 \mathrm{~cm}$ thick steel plates, whereas a glass window is installed in the fourth bay. The double-window cabinet is also characterized by a vertical steel element that separates two glass windows. The vertical steel columns are modeled with beam elements in SAP 2000, according to their actual geometry (Fig. 2). The presence of the steel horizontal plates is modeled through four horizontal beam elements both at the top and at $17 \mathrm{~cm}$ from the base. Two diaphragm constraints are imposed between the nodes at the top and at $17 \mathrm{~cm}$ height. Bidimensional elements are adopted to model glass windows. Further details on the developed models can be found in (Di Sarno et al. 2015a). Different masses are inserted at the shelf levels, according to the actual mass adopted in the experimental phase for the different test groups. Dynamic features of the cabinets are summarized in Table 2. 
Vertical nonlinear links, i.e. nonlinear springs, are added at the base of the cabinets. They are characterized by compression-only behavior in order to model the restraint of a freestanding cabinet at its base. Vertical loads are applied at the top of the cabinets, simulating their own weight, as shown in Fig. 2. Finally, damping ratio is assumed equal to the experimental damping ratio, evaluated in (Di Sarno et al. 2015a). Nonlinear dynamic analyses are performed on the defined models. Recorded table accelerations are applied at the base of both cabinets for the three different test groups. Top cabinet horizontal accelerations resulting from numerical model are compared to recorded horizontal accelerations for two different tests at two different intensities (see Figs. 3, 4). A close numerical-to-experimental matching is observed for low-intensity shake table tests (Fig. 3), when the cabinet is laterally deforming without any evident rocking mechanism. At larger amplitudes, i.e. peak table acceleration larger than the theoretical value $b / h \cdot g$, the FEM model is not capable to reproduce the recorded accelerations (Fig. 4), particularly due to the presence of some spikes in the recorded accelerograms. These spikes are caused by the occurrence of a rocking mechanism, as highlighted in (Cosenza et al. 2014). It can be therefore concluded that the developed numerical model is efficient until the cabinet exhibits the rocking mechanism. The numerical-experimental comparison is performed for all experimental tests. The same comments can be drawn from such comparisons, which are omitted here for the sake of brevity.

The evaluation of the seismic intensity required to record the rocking mechanism in the cabinet becomes therefore essential. The occurrence of such mechanism can be checked from the onset of tension displacement in the link element. Vertical displacements of both front and rear links can be plotted on the same graph of the recorded top cabinet horizontal accelerations (Fig. 5). Negligible vertical displacements are recorded in both front and rear links in case cabinets do not exhibit rocking mechanism, e.g. the test characterized by $0.126 \mathrm{~g}$ peak table acceleration in test group 100. Large vertical tension displacements in links are instead highlighted as seismic intensity increases. Significant vertical displacements are recorded in links for all the tests which show rocking mechanism, e.g. the test characterized by $0.483 \mathrm{~g}$ peak table acceleration in test group 200 (Fig. 5). It should be noted that the theoretical peak table acceleration $b / h \cdot g$ can be used as a threshold value for rocking mechanism, where $b$ and $h$ are cabinet semi-width and semi-height (as detailed in Sect. 4.1), respectively, and $g$ is the acceleration of gravity. Such a threshold value is equal to 0.26 and $0.23 \mathrm{~g}$ for single- and double-window cabinets respectively.

A time correlation of the rocking mechanism with the tension displacement in the links can be also highlighted: the spikes in the experimental horizontal acceleration time-history typically occur after the vertical link experiences the uplift, as clearly visible in Fig. 5a. The defined model is therefore able to recognize the occurrence of the rocking mechanism in the cabinets, which is denoted by vertical tension displacements in the link at the base of the cabinets.

Table 2 Dynamic properties of the modelled cabinets in terms of natural frequency and damping ratio

\begin{tabular}{llllll}
\hline Test group & \multicolumn{2}{l}{ Single-window cabinet } & & \multicolumn{2}{l}{ Double-window cabinet } \\
\cline { 2 - 3 } \cline { 5 - 6 } & $f(\mathrm{~Hz})$ & $\xi(\%)$ & & $f(\mathrm{~Hz})$ & $\xi(\%)$ \\
\hline 100 & 7.38 & 12.1 & & 5.08 & 17.5 \\
200 & 8.84 & 14.0 & & 5.57 & 18.8 \\
300 & 8.21 & 12.3 & & 5.30 & 14.6 \\
\hline
\end{tabular}


(a)

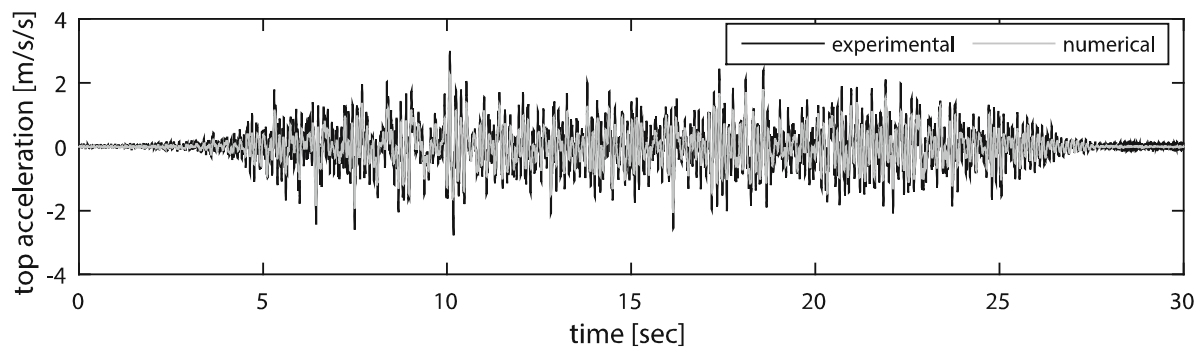

(b)

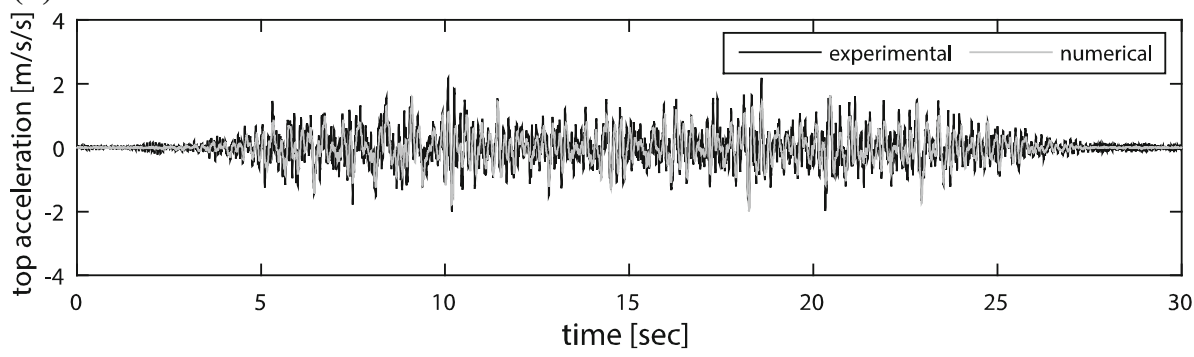

Fig. 3 Comparison between FEM model and experimental results in test group 100 (test 101) for a singlewindow cabinet and $\mathbf{b}$ double-window cabinet
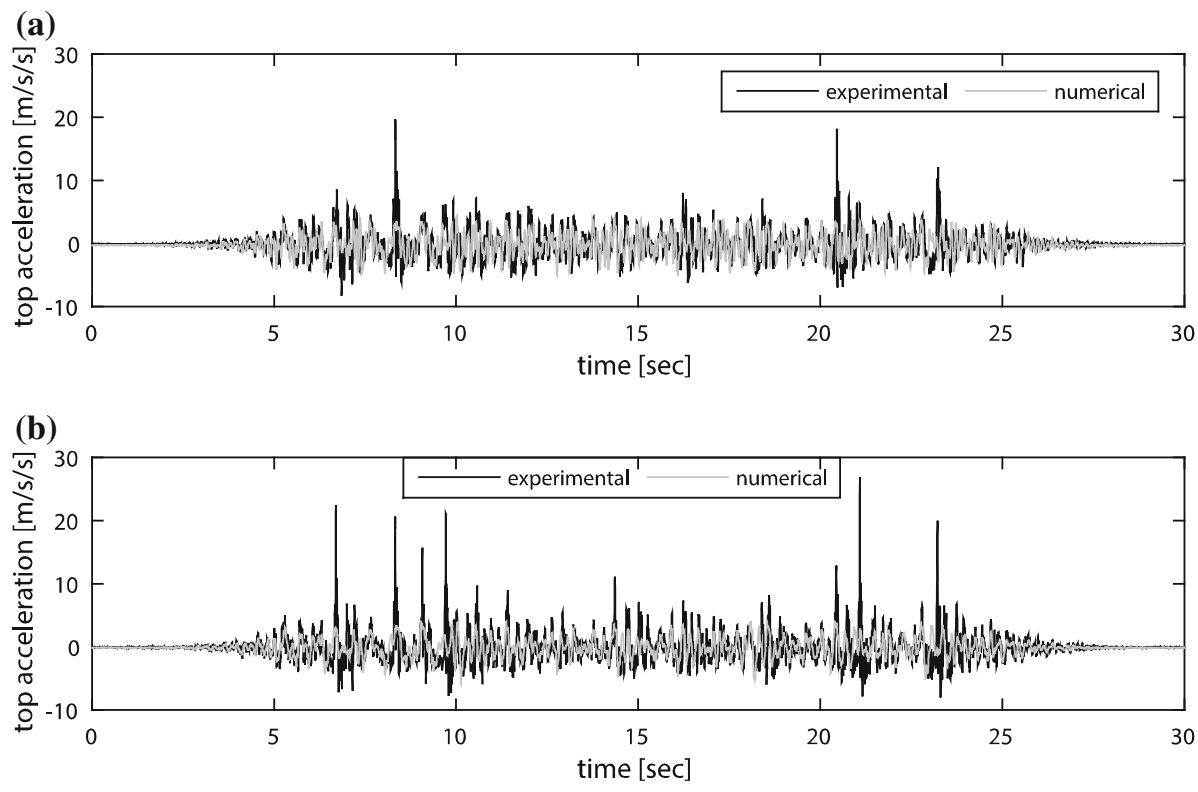

Fig. 4 Comparison between FEM model and experimental results in test group 200 (test 204) for a singlewindow cabinet and $\mathbf{b}$ double-window cabinet 
(a)

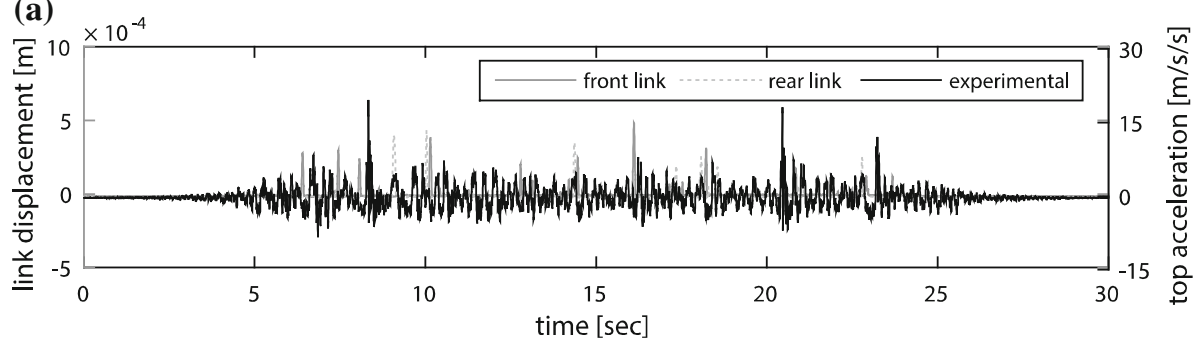

(b)

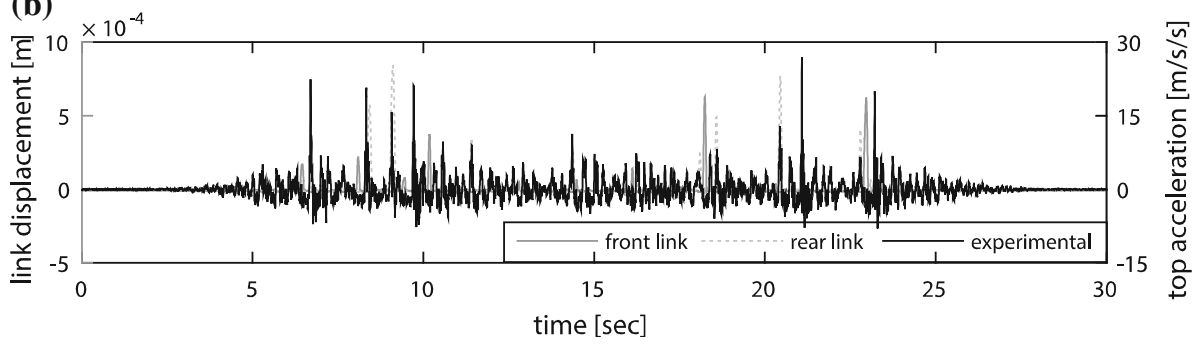

Fig. 5 Experimental top cabinet acceleration and link vertical displacement in test group 200 (test 204) for a single-window cabinet and $\mathbf{b}$ double-window cabinet

\subsection{Horizontal acceleration pattern along the height of the cabinets}

Horizontal acceleration pattern along the height of the cabinets should be carefully assessed in order to both evaluate the global overturning moment acting on the cabinet and predict the acceleration demand on the contents positioned at the different shelves of the cabinets. The overturning moment should be evaluated to assess the occurrence of possible rocking mechanisms i.e. when overturning moment exceeds stabilizing moment due to gravity loads. This exercise is needed in order to assess the applicability of FEM modeling technique. The acceleration demand on the contents should be assessed to protect them against sliding and/or overturning.

Simplified code-approaches implemented in the international seismic standards, e.g. Eurocode 8 (EC8) (CEN 2004) and ASCE7 (American Society of Civil Engineers 2010), assume that the seismic demand force acts in the center of mass of the component. Moreover, the different research studies focus on the evaluation of the floor response spectra; the acceleration distribution along the height of the component, which strongly influences the demand in components characterized by multiple masses and modes of vibration, is typically not investigated. FEMA P-750 (FEMA P-750 2009), in the commentary to the chapter on the seismic design requirements for nonstructural components, includes a detailed discussion about the ASCE7 predictive equation. It is stated that "the requirements are intended to apply only to permanently attached components" and "Storage cabinets, tall bookshelves, and other items of significant mass do not fall into this category and should be anchored or braced in accordance with this chapter". Hence, the need for the evaluation of a predictive formula for freestanding nonstructural components is implicitly claimed. 
The horizontal acceleration pattern along the height of the freestanding components is investigated in this section. The study is limited to the cases where freestanding components do not exhibit any rocking mechanism; in such a case the motivations of the study, i.e. evaluate overturning moment and demand on the contents on the shelves, are no longer valid since the operational limit state is certainly exceeded. Horizontal accelerations are recorded at four different levels of the cabinets in order to analyze the distribution of seismic demand along the height of the tested components. In particular, accelerometers $S c 1, S c 2, S c 3$ and $S c 4$ are positioned on the single-window cabinet at 0.10, 0.40, 0.70 and 1.00 normalized height from the base, respectively; accelerometers $D c 1, D c 2, D c 3$ and $D c 4$ are placed on the double-window cabinet at $0.08,0.39,0.70,1.00$ normalized height from the base, respectively.

The horizontal accelerations recorded along the height of the cabinets during the test group 100, corresponding to 0.37 g peak table acceleration, are shown in Fig. 6 and in Fig. 7. The filtering and amplification effects of the two tested cabinets are clearly visible in the recorded accelerograms. The accelerogram at the top of the cabinet has broader frequency contents than the base accelerogram in the vicinity of the natural frequency of the cabinet, whereas the frequency content at larger frequency is reduced passing from the base to the top of the component. This outcome is also confirmed by the periodgrams of the different recorded signals from the base to the top of the components, omitted here for the sake of brevity, which highlight an increasing frequency content close to the natural frequencies of the components from their base to their top.

The recorded maximum horizontal accelerations on the cabinets are also normalized to the maximum acceleration at their base, i.e. the PFA, in order to generalize the results. The maximum accelerations recorded on the cabinets during each test (in gray), normalized with respect to the PFA, and their mean (in black), are represented in Fig. 8 for both

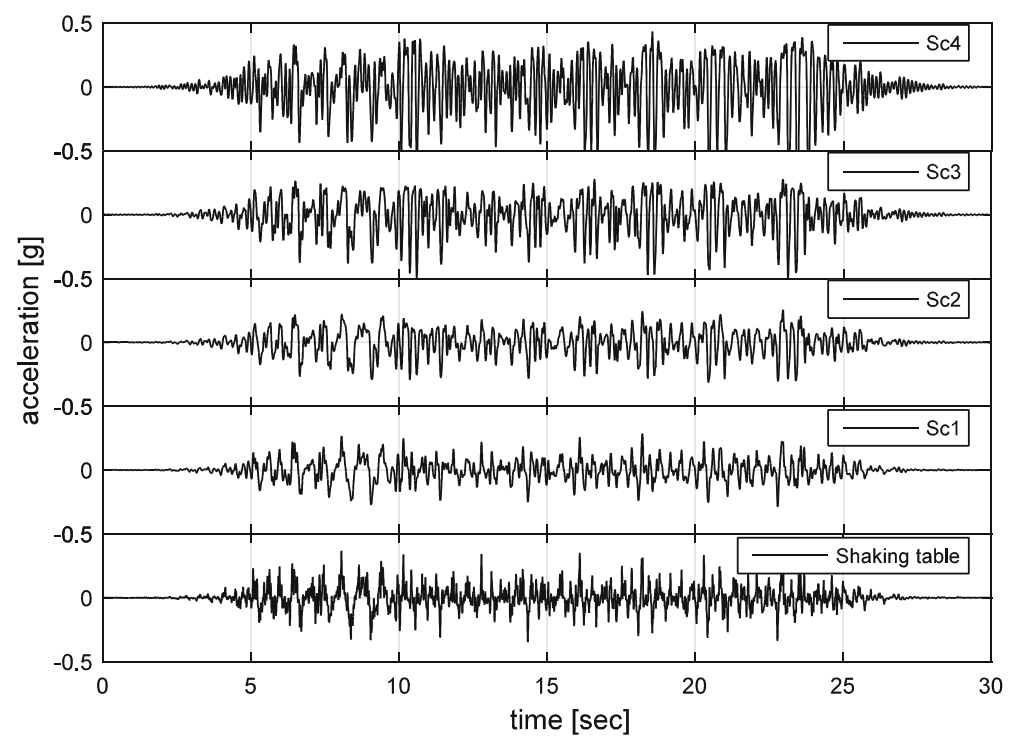

Fig. 6 Horizontal accelerograms recorded on the single-window cabinet during the test group 100, corresponding to $0.37 \mathrm{~g}$ peak table acceleration 


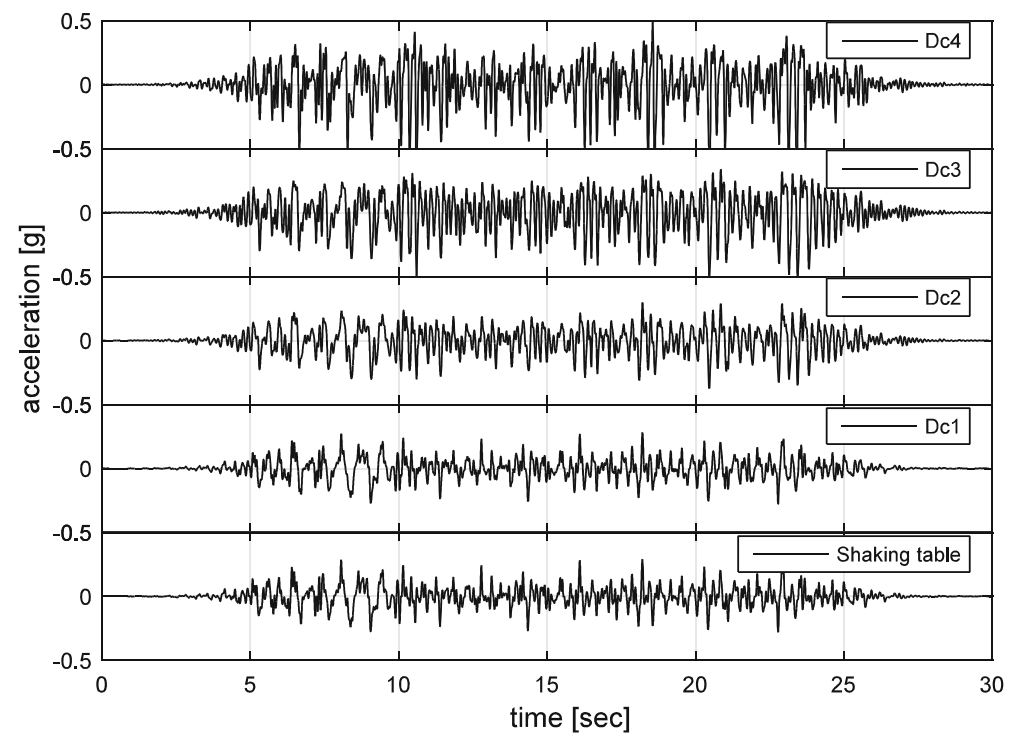

Fig. 7 Horizontal accelerograms recorded on the double-window cabinet during the test group 100, corresponding to $0.37 \mathrm{~g}$ peak table acceleration
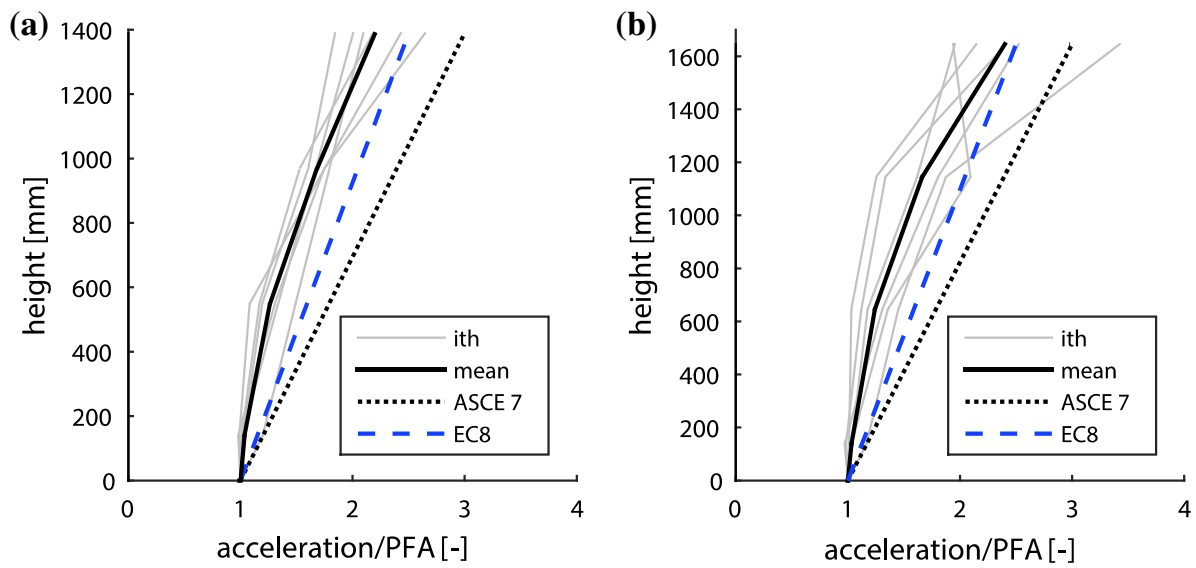

Fig. 8 Trend of the horizontal accelerations along the height for the different performed tests (gray and black lines) compared to the structural floor acceleration trend provisions included in ASCE 7 and EC8 (dotted lines) for a single-window and $\mathbf{b}$ double-window cabinets

double- and single-window cabinets. These diagrams are compared with the trend of the horizontal floor accelerations in buildings, provided by ASCE 7 (American Society of Civil Engineers 2010) and EC8 (CEN 2004). The acceleration provided by ASCE 7 is linearly distributed from PGA at the base to a tripled value at the top. Eurocode 8 provides a similar criterion, assuming a top acceleration value equal to 2.5 times the peak ground acceleration. The structural horizontal acceleration profile along the building height provided by EC8 leads to a close fit of the horizontal acceleration pattern measured on the tested freestanding cabinets, while ASCE 7 trend lightly overestimates the experimental results. 
The freestanding components can be therefore treated as a structural system vibrating at a generic building story. In the following a comparison between this proposal and the current EC8 provisions for computing the demand on nonstructural components is briefly discussed.

Eurocode 8 assumes that the seismic force on a nonstructural component should be applied as a point load at its mass centroid. Such a point load is simply evaluated by multiplying its mass with the maximum acceleration acting on the component. The maximum acceleration on the component is evaluated multiplying the peak floor acceleration with a component amplification factor, i.e. ratio between maximum acceleration on the component and PFA. The component amplification factor ranges from 2.2 to 2.5 depending on the position of the component within the structure. It is found that the overturning moment produced by such a force is $20 \%$ larger than the moment induced by the proposed distribution (dotted blue line in Fig. 8), while the shear overestimation is larger than $30 \%$, assuming a component amplification factor equal to 2.5 .

\section{Model for post-rocking behavior}

Medical components, such as the tested cabinets, typically exhibit a rocking behavior as the seismic intensity increases. Thus, rigid block model becomes a good candidate to model the dynamic response of these components. In this study, tested cabinets are modeled as equivalent rigid blocks and subjected to the experimental base accelerations (Sect. 4.1); the ability to predict the occurrence of both rocking mechanism and overturning is verified. Given the good model fidelity, a preliminary study is presented in Sect. 5, which is aimed to the identification of the most efficient seismic intensity measure (IM) for rigid blocks and the influence of the geometric properties of rigid blocks on their dynamic performance.

\subsection{Rigid block models}

As previously discussed, tested cabinets may be also modeled as rigid blocks. Their dynamic behavior was extensively investigated in past decades, e.g. (Dimitrakopoulos and DeJong 2012; Dimitrakopoulos and Paraskeva 2015; Housner 1963; Ishiyama 1982; Makris and Konstantinidis 2003; Yim et al. 1980; Zhang and Makris 2001), among many others. A rigid block may be set into rocking or move rigidly with the ground, depending on its geometric features; if it sets into rocking, it will oscillate about two centers of rotation at its base corners. In this study it is assumed that the block and base surfaces in contact are perfectly smooth so that the block will rock around the edges and no intermediate location. Moreover, the coefficient of friction is assumed to be sufficiently large so that there will be no sliding between the block and the base. This assumption is typically valid for the tested cabinets, given their slenderness and interface material with the floor. It is assumed that the mass is uniformly distributed within the cabinet. The rigid block is freestanding without any lateral restraint: the restraint provided by the rear wall, which in the reference tests (Cosenza et al. 2014) is positioned at $2 \mathrm{~cm}$ distance from the cabinet, is not modeled.

The equation of motion of the rigid block subjected to a predefined base motion $\ddot{u}_{g}(t)$ is derived by considering the equilibrium of moments about the centers of rotation: 


$$
\ddot{\theta}(t)=-p^{2}\left\{\sin [\alpha \operatorname{sgn}[\theta(t)]-\theta(t)]+\frac{\ddot{u}_{g}(t)}{g} \cos [\alpha \operatorname{sgn}[\theta(t)]-\theta(t)]\right\}
$$

where $\theta$ is the rigid block rotation, $g$ is the acceleration of gravity, $p$ is the frequency parameter of the block and $\alpha$ is the critical angle (Fig. 9). The equation of motion is developed and adopted in several existing studies, e.g. (Makris and Konstantinidis 2003), among others. In this study it is solved through Runge-Kutta Ordinary Differential Equations (ODE) solver, available in Matlab (The MathWorks Inc. 2015).

Rocking mechanism occurs alternatively around $\mathrm{O}$ and $\mathrm{O}^{\prime}$ (Fig. 9). It is assumed that the rotation continues smoothly from point $\mathrm{O}$ to $\mathrm{O}^{\prime}$, when the angle of rotation reverses (Makris and Konstantinidis 2003). A reduction of the angular velocity is imposed when the rotation reverses, in order to take into account the energy loss at every impact (Housner 1963). Such a reduction is evaluated by equating angular momentum about $O$ just before and immediately after the impact. The coefficient of restitution, i.e. the ratio between angular velocities after and before the impact, is evaluated as follows:

$$
e=1-1.5 \sin ^{2} \alpha
$$

Single-window cabinet is modelled as a rigid block characterized by $0.36 \mathrm{~m}$ base $(2 b$ in Fig. 9) and $1.39 \mathrm{~m}$ height ( $2 h$ in Fig. 9). Double window cabinet is modeled assuming $0.38 \mathrm{~m}$ base and $1.65 \mathrm{~m}$ height. Critical angles $\alpha$ are therefore 0.250 and $0.224 \mathrm{rad}$ for single-window and double-window cabinets, respectively.

These models are subjected to the acceleration time history recorded at the base of the cabinets for the different tests. Since the adopted model is not influenced by the mass distribution, it is subjected only to the test group 100 shakings. The response of the rigid block simulating the single-window cabinet under three different input motions is shown in Fig. 10. The three responses refer to different input intensities which produce (a) negligible rocking rotations, (b) initiation of rocking response and (c) block overturning. The seismic

Fig. 9 Rigid block geometry and parameters

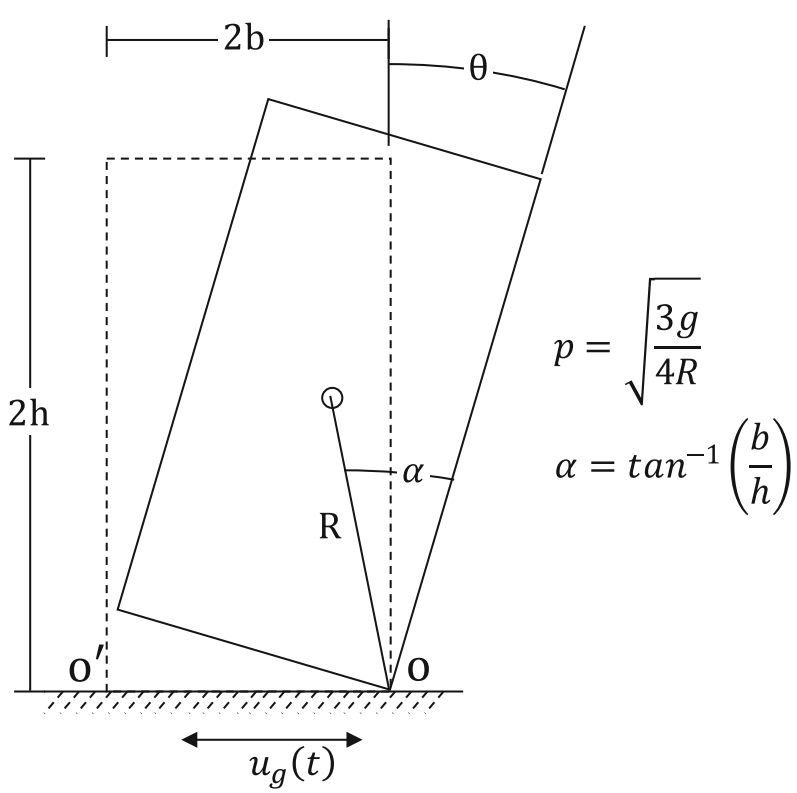


(a)
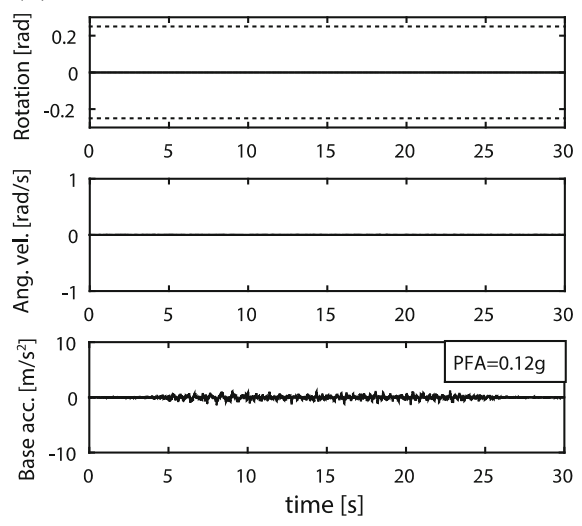

(b)
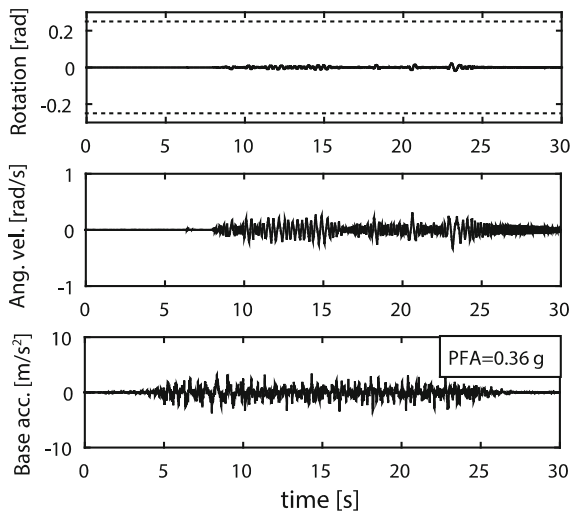

(c)
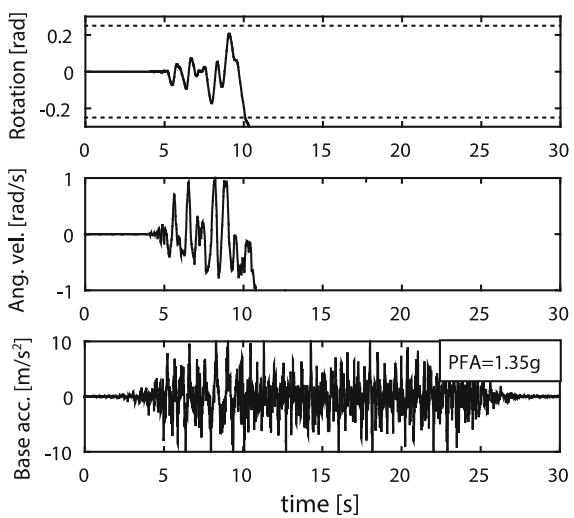

Fig. 10 Single-window rigid block response to three different input motions recorded in test group 100

intensities required to attain rocking and overturning, expressed in terms of PFA, are compared for both single- and double-window cabinets with the experimental evidence (Table 3).

The adopted numerical model is able to foresee the occurrence of rocking mechanism. However, an overestimation of the PFA, i.e. peak acceleration at the base of the block, which causes overturning is also shown. This overestimation may be caused by the assumption that the tested cabinets behave as rigid blocks, whereas they are also characterized by a significant flexibility (Di Sarno et al. 2015a). Moreover, the numerical model assumes that the mass is uniformly distributed within the cabinet and neglects the presence of the wall behind the cabinets. These assumptions may have caused such an unsafe-sided estimation of the PFA overturning threshold.

The analyses are also performed neglecting the reduction of the velocity after the impact, i.e. a 1.0 coefficient of restitution is considered. The numerical-to-experimental comparison is shown in Table 3. It is shown that the rocking initiation is still well predicted, since it is not influenced by the coefficient of restitution. Moreover, a safe-sided estimation of the overturning PFA threshold is generally demonstrated, in case a 1.0 coefficient of restitution is assumed. It is therefore demonstrated that the rigid block 


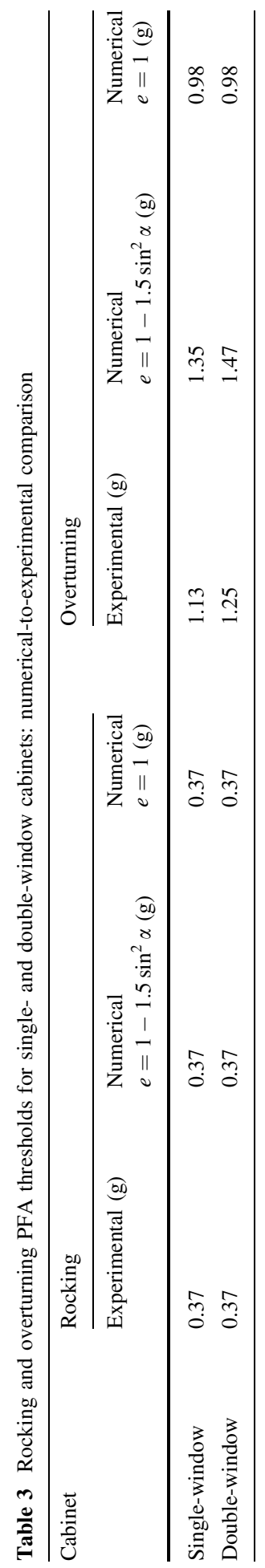


models of tested cabinets can give a safe-sided prediction of the seismic intensity required to induce overturning, provided that a 1.0 coefficient of restitution is assumed. Current and future studies will deal with the refinement of such simple models, e.g. trying to incorporate in the model the external restraint provided by the wall.

\section{Dynamic analysis of rigid blocks}

The experimental-to-numerical comparison described in the previous section demonstrates that hospital building cabinets overturning can be modeled by means of rigid blocks. The question arises as to which intensity measure (IM) is well correlated to the seismic demand on rigid blocks. From a performance-based earthquake engineering perspective, the identification of an efficient intensity measure which is valid for a generic rigid block assumes a key role, as well as the assessment of fragility curves for loss assessment (De Biasio et al. 2015). A fragility study of rigid blocks is therefore conducted and aimed to two different objectives: (a) assessment of the most efficient IM; (b) influence of geometric properties of the rigid block on its performance.

The assessment of the most efficient IM is conducted on two rigid blocks. Rigid block no. 1 is the block representative of the single-window cabinet, with $R=0.717 \mathrm{~m}$ and $h / b=3.9$; rigid block no. 2 is taken from Yim et al. (1980) and is characterized by a $3.05 \mathrm{~m}$ (10 feet) $R$ and an aspect ratio $h / b$ equal to 5 (Fig. 9). The two blocks are respectively representative of a typical cabinet and a large rigid block, in order to investigate the influence of the geometry of the block on the seismic response. The blocks are subjected to incremental dynamic analyses, using the set of accelerograms included in ATC 63 (Applied Technology Council 2008). The latter document includes two different datasets: (a) a far field and (b) a near field dataset. Far field and near field record sets are used to study the rigid block dynamic behavior. The amplitude of vibration decreases with increasing distance from the epicenter in far field input, and the strong motion record moves to lower frequencies for the effects of selective absorption. The decay of the amplitude does not occur with regularity and the characteristics of the shaking are governed mainly by the focal mechanisms in near fault conditions.

Two Damage States (DSs) are defined to study the rigid block fragility during the numerical simulation: a rocking damage state and a collapse damage state. The rigid block reaches the rocking damage state when the rotation is larger than a conventionally small value, say $0.01 \alpha$, whereas it attains the collapse damage state when the rotation is larger than the critical angle $\alpha$ (Fig. 9). Porter method "A" (Porter et al. 2007) is employed to create the lognormal fragility curves according to the different intensity measures. This methodology allows assessing the fragility curve lognormal distribution which best fits numerical data, i.e. IMs required to reach a given damage state for each accelerogram. In particular, the median and the logarithmic standard deviation can be estimated as

$$
\begin{gathered}
x_{m}=\exp \left(\frac{1}{M} \sum_{1=1}^{M} r_{i}\right) \\
\beta=\sqrt{\frac{1}{M-1} \sum_{i=1}^{M}\left[\ln \left(\frac{r_{i}}{x_{m}}\right)\right]^{2}}
\end{gathered}
$$


where $M$ is the number of accelerograms, $r_{i}$ is the intensity measure required to reach a given damage state for each accelerogram. Different Intensity Measures (IMs) are adopted to plot the fragility curves (Table 4) among the ones typically adopted in literature studies (Cosenza and Manfredi 2000). Several typical IMs are considered among the most commonly adopted in earthquake engineering. Three IMs are taken from literature, i.e. $I M_{4}$, $I M_{5}$ and $I M_{6}$ : they are defined as dimensionless slenderness IMs. Fragility curves in terms of peak ground acceleration (PGA) and velocity (PGV) are shown in Fig. 11 for both the damage states and the suite of sample accelerograms. Input type may influence the fragility curve: it is shown that median IM values required to reach a given damage state may significantly vary from far field to near field input motions. The influence of the set of accelerograms on the fragility curve could be more/less evident depending on the damage state, as shown in Fig. 11 for both PGA and PGV.

An IM is efficient when it induces a small variability of a damage measure for a given IM (Luco and Cornell 2007); an efficient IM would allow reducing the number of nonlinear dynamic analyses required to assess the fragility curve with adequate precision (Shome and Cornell 1999). The efficiency of an IM is typically assessed from the dispersion of the engineering demand parameter (EDP) at a given IM level, e.g. (Donaire-Ávila et al. 2015)

Table 4 Intensity measures considered in the assessment of fragility curves

\begin{tabular}{|c|c|c|}
\hline $\begin{array}{l}\text { Intensity } \\
\text { measure }\end{array}$ & Definition & \\
\hline$P G A$ & $P G A=\max \left\{\left|a_{g}(t)\right|\right\}$ & $\begin{array}{l}\text { Peak ground acceleration } \\
a_{g}(t) \text { is the ground acceleration time-history }\end{array}$ \\
\hline$P G V$ & $P G V=\max \left\{\left|v_{g}(t)\right|\right\}$ & $\begin{array}{l}\text { Peak ground velocity } \\
v_{g}(t) \text { is the ground velocity time-history }\end{array}$ \\
\hline$I_{A}$ & $\frac{\pi}{2 \cdot g} \int_{0}^{t} a_{g}^{2}(t) d t$ & $\begin{array}{l}\text { Arias intensity (Arias } 1970 \text { ) } \\
g \text { is the acceleration of gravity }\end{array}$ \\
\hline$I M_{4}$ & $\frac{P G A}{g \tan \alpha}$ & $\begin{array}{l}\text { Normalized intensity measure, taken from (Dimitrakopoulos and } \\
\text { Paraskeva 2015) }\end{array}$ \\
\hline$I M_{5}$ & $\frac{p P G V}{g \tan \alpha}$ & $\begin{array}{l}\text { Normalized intensity measure, taken from (Dimitrakopoulos and } \\
\text { Paraskeva 2015) }\end{array}$ \\
\hline$I M_{6}$ & $\frac{\omega_{m} P G V}{g \tan \alpha}$ & $\begin{array}{l}\text { Normalized intensity measure, taken from (Dimitrakopoulos and } \\
\text { Paraskeva 2015) } \\
\omega_{m}=2 \pi / T_{m}, T_{m} \text { is earthquake mean period (Dimitrakopoulos } \\
\text { et al. 2009) }\end{array}$ \\
\hline$I M_{\text {Fajfar }}$ & $P G V t_{d}^{0.25}$ & $\begin{array}{l}\text { Fajfar intensity, where } t_{d} \text { is the significant duration (Fajfar et al. } \\
\text { 1990) }\end{array}$ \\
\hline$C A V$ & $\int_{0}^{t_{f}}\left|a_{g}(t)\right| d t$ & Cumulative absolute velocity \\
\hline$A S I$ & $\int_{0.1}^{0.5} S_{a}(T, \xi) d T$ & $\begin{array}{l}\text { Acceleration Spectral Intensity } \\
S_{a} \text { is the pseudo-spectral acceleration } \\
0.02 \text { damping ratio is assumed }\end{array}$ \\
\hline$S_{a}\left(T_{p}\right)$ & $S_{a}\left(T_{p}\right)$ & Spectral acceleration at $T_{p}=\frac{2 \pi}{p}$ \\
\hline$S_{v}\left(T_{p}\right)$ & $\frac{S_{a}\left(T_{p}\right)}{p}$ & Spectral velocity at $T_{p}=\frac{2 \pi}{p}$ \\
\hline$H I$ & $\int_{0.1}^{2.5} S_{v}(T, \xi) d T$ & $\begin{array}{l}\text { Housner Intensity }(H I) \text { (Housner 1952) } \\
0.02 \text { damping ratio is assumed }\end{array}$ \\
\hline
\end{tabular}



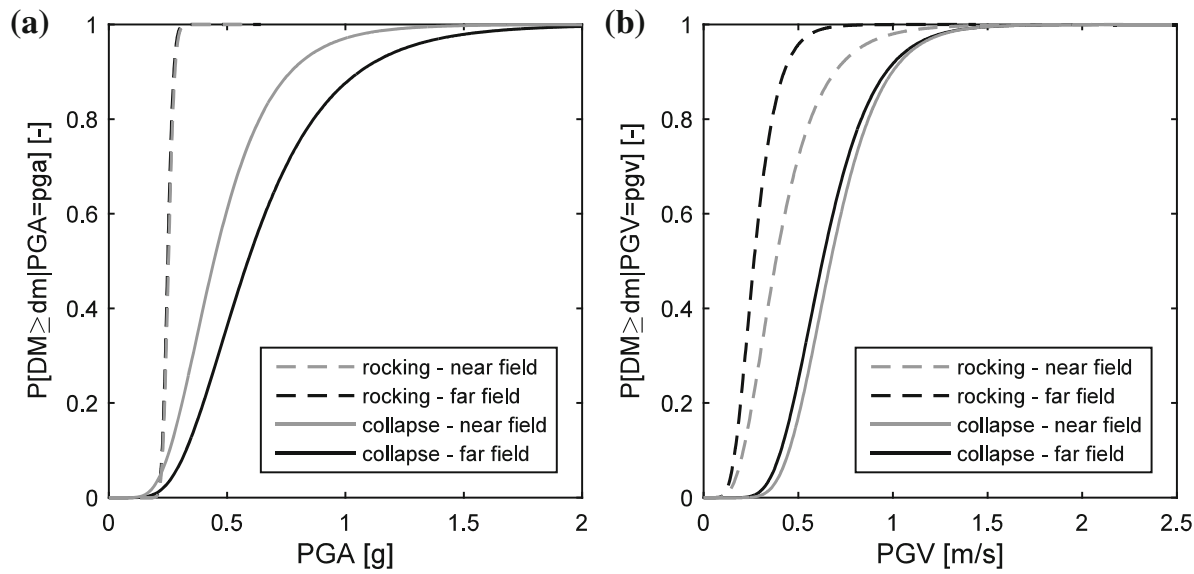

Fig. 11 Rigid block fragility curves for far-field and near-field inputs considering both a PGA and b PGV as IM for rigid block no. 2

among many others. For rigid blocks, it should be considered that the occurrence of rocking or overturning is far more important than the attainment of a given engineering demand parameter, e.g. rigid block rotation $\theta$. The behavior of (and the consequences on) the rigid block is not significantly influenced by the amplitude of the rigid block motion, provided it is smaller than the critical angle $\alpha$. Thus, IM efficiency can be directly measured from the standard deviation $\beta$ of the fragility curves: the smaller the standard deviation the more efficient the IM. Table 5 includes the logarithmic standard deviation $\beta$ of the different fragility curves, assessed for the different IMs and sets of accelerograms. Table 5 shows that $P G A$ and $I M_{4}$, which is derived from $P G A$, are well correlated to the occurrence of the rocking mechanism. This can be justified considering that rocking mechanism is observed when overturning moment exceeds stabilizing moment due to gravity loads; simple equilibrium calculations yield that the minimum acceleration required to let the block rock is $b / h \cdot g$, which is consistent with the observed median values of the fragility curves for the rigid blocks. Median $P G A-I M_{4}$ values are about $20 \%$ larger than expected from rotational equilibrium, due to (a) the dynamic nature of the motion and (b) the finite threshold value associated to the occurrence of rocking.

Collapse/overturning damage state is better correlated to $P G V-I M_{5}$ than $P G A-I M_{4}$ for the rigid block no. 2, as highlighted by the smaller dispersion of the fragility curve in terms of $P G V-I M_{5}$. The standard deviations of the dimensionless intensity measures $I M_{4}=\frac{P G A}{g \tan \alpha}$ and $I M_{5}=\frac{p P G V}{g \tan \alpha}$ are equal to the corresponding deviations for $P G A$ and $P G V$, respectively, since the dimensionless IMs are directly estimated from $P G A$ and $P G V$ through some geometric parameters of the investigated block. $I M_{\text {Fajfar }}$ intensity measure, which is based on PGV, also provides a good efficiency in predicting overturning of rigid block no. 2. For the tested cabinet, i.e. rigid block no.1, it is noted that PGA is the most efficient IM. The outcomes of the analysis on these two blocks do not allow a unique identification of the efficient IM for overturning. It is interesting to note that the dispersion values for the most efficient IMs are not sensitive to the seismic input type, i.e. near-field and far-field motions produce similar dispersion values for the selected rigid blocks.

Since there was no agreement between the two selected rigid blocks, other four rigid blocks are considered for each of the two rigid blocks by modifying alternatively their 
Table 5 Fragility curve logarithmic standard deviation for different intensity measures; lowest standard deviation values for rocking and overturning are in bold

\begin{tabular}{|c|c|c|c|c|c|c|c|c|}
\hline \multirow[t]{3}{*}{ IM } & \multicolumn{4}{|c|}{ Rocking } & \multicolumn{4}{|c|}{ Overturning } \\
\hline & \multicolumn{2}{|c|}{ Far field } & \multicolumn{2}{|c|}{ Near field } & \multicolumn{2}{|c|}{ Far field } & \multicolumn{2}{|c|}{ Near field } \\
\hline & $\begin{array}{l}\text { Block } \\
\text { no. } 1\end{array}$ & $\begin{array}{l}\text { Block } \\
\text { no. } 2\end{array}$ & $\begin{array}{l}\text { Block } \\
\text { no. } 1\end{array}$ & $\begin{array}{l}\text { Block } \\
\text { no. } 2\end{array}$ & $\begin{array}{l}\text { Block } \\
\text { no. } 1\end{array}$ & $\begin{array}{l}\text { Block } \\
\text { no. } 2\end{array}$ & $\begin{array}{l}\text { Block } \\
\text { no. } 1\end{array}$ & $\begin{array}{l}\text { Block } \\
\text { no. } 2\end{array}$ \\
\hline$P G A(g)$ & 0.063 & 0.078 & 0.066 & 0.080 & 0.230 & 0.459 & 0.208 & 0.428 \\
\hline$P G V(\mathrm{~m} / \mathrm{s})$ & 0.360 & 0.367 & 0.470 & 0.468 & 0.338 & 0.335 & 0.398 & 0.309 \\
\hline$I_{A}(\mathrm{~m} / \mathrm{s})$ & 0.583 & 0.561 & 0.853 & 0.883 & 0.644 & 0.880 & 0.920 & 0.881 \\
\hline$I M_{4}$ & 0.063 & 0.078 & 0.066 & 0.080 & 0.230 & 0.459 & 0.208 & 0.428 \\
\hline$I M_{5}$ & 0.360 & 0.367 & 0.470 & 0.468 & 0.338 & 0.335 & 0.398 & 0.309 \\
\hline$I M_{6}$ & 0.245 & 0.244 & 0.312 & 0.296 & 0.312 & 0.445 & 0.400 & 0.522 \\
\hline$I M_{\text {Fajfar }}$ & 0.385 & 0.392 & 0.509 & 0.513 & 0.357 & 0.310 & 0.452 & 0.358 \\
\hline$C A V(\mathrm{~m} / \mathrm{s})$ & 0.578 & 0.567 & 0.816 & 0.832 & 0.584 & 0.588 & 0.816 & 0.766 \\
\hline$A S I(\mathrm{~m} / \mathrm{s})$ & 0.173 & 0.156 & 0.265 & 0.251 & 0.248 & 0.486 & 0.271 & 0.427 \\
\hline$S_{a}\left(T_{p}\right)(\mathrm{g})$ & 0.576 & 0.770 & 0.600 & 0.721 & 0.510 & 0.481 & 0.494 & 0.519 \\
\hline$S_{v}\left(T_{p}\right)(\mathrm{m} / \mathrm{s})$ & 0.576 & 0.770 & 0.600 & 0.721 & 0.510 & 0.481 & 0.494 & 0.519 \\
\hline$H I(\mathrm{~m})$ & 0.173 & 0.156 & 0.265 & 0.251 & 0.248 & 0.486 & 0.271 & 0.427 \\
\hline
\end{tabular}

slenderness $h / b$ and dimension $R$. The four rigid blocks obtained from the single window cabinet are characterized by (a) $R=1.43 \mathrm{~m}$ and $h / b=3.91$; (b) $R=0.359 \mathrm{~m}$ and $h / b=3.91$; (c) $R=0.717 \mathrm{~m}$ and $h / b=7.83$; (d) $R=0.717 \mathrm{~m}$ and $h / b=1.96$. The four rigid blocks corresponding to the block by Yim et al. are characterized by (a) $R=1.52 \mathrm{~m}$ (5 feet) and $h / b=5.0$; (b) $R=4.57 \mathrm{~m}$ (15 feet) and $h / b=5.0$; (c) $R=3.05 \mathrm{~m}$ (10 feet) and $h / b=2.5$; (d) $R=3.05 \mathrm{~m}$ (10 feet) and $h / b=7.5$. Incremental dynamic analysis with the two above mentioned sets of accelerograms are performed and lognormal fragility curves are estimated for each block subjected to each input motion set, as detailed above.

It is confirmed that $P G A$ and $I M_{4}$ are the most efficient IMs for rocking, while the most efficient IM for overturning is influenced by the dimension $R$ of the block (Fig. 12a). The dispersion of $P G V-I M_{5}$ overturning fragility curves is not influenced by $R$; it is included in the range between 0.3 and 0.4 for the different blocks and input considered. The logarithmic standard deviation of $P G A-I M_{4}$ overturning fragility curves is influenced by the dimension of the block; an increase in $R$ corresponds to an increase in $\beta$. It is concluded that $P G A-I M_{4}$ are the most efficient IMs for small rigid blocks, say R smaller than $1.0 \mathrm{~m}$, whereas $P G V-I M_{5}$ are more efficient for large rigid blocks, say $\mathrm{R}$ larger than $2.0 \mathrm{~m}$. Housner (1963) also suggested that the overturning of blocks was well correlated to the energy required to uplift and rotate the block by an $\alpha$ angle, which can be inferred by the peak velocity. For intermediate $R$ values the efficiency of $P G A-I M_{4}$ and $P G V-I M_{5}$ is similar. This phenomenon is caused by the fact that overturning fragility increases as dimension $R$ decreases, as also discussed in (Housner 1963; Makris and Vassiliou 2014). In particular, very small rigid blocks tend to overturn as soon as they start rocking, as highlighted by the discrepancy between median rocking PGA and median overturning PGA (Fig. 12b) for the ten different rigid blocks considered herein. It is interesting to note that the ratio in Fig. $12 \mathrm{~b}$ tends to zero as the dimension $R$ tends to 0 . At such small $R$ 

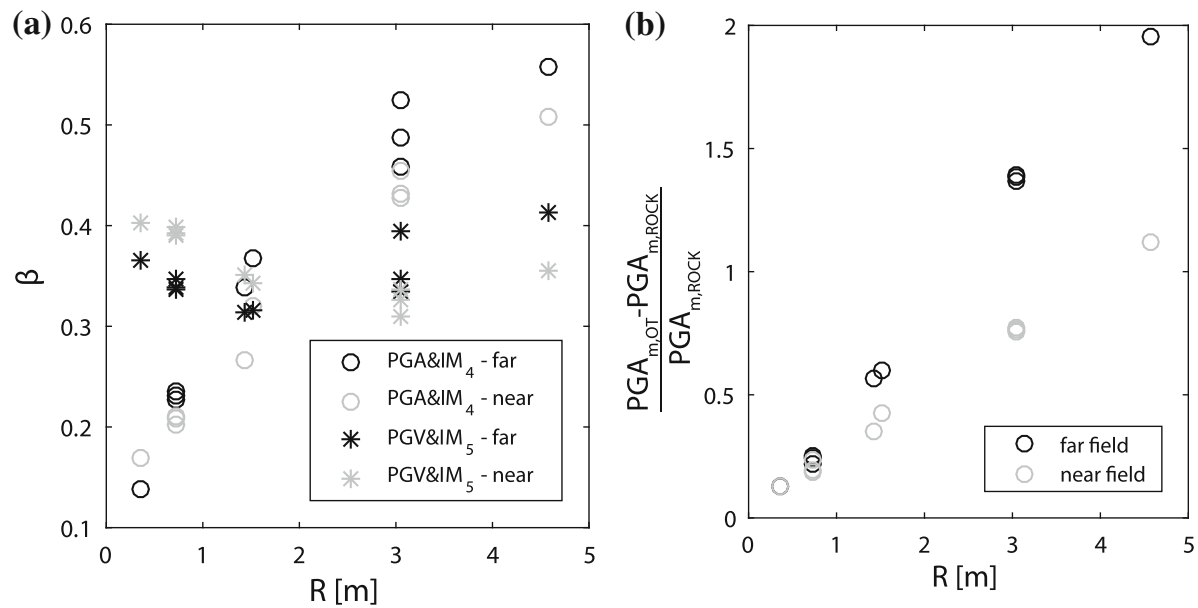

Fig. 12 a Logarithmic standard deviation of overturning fragility curves for different rigid blocks and b discrepancy among overturning median PGA and rocking PGA

values, the dispersion of the overturning fragility curve (Fig. 12a) tends to be the same as the rocking fragility curves, which is in the range $0.05-0.08$ for the different rigid blocks. Very small rigid blocks, say $R<1.0 \mathrm{~m}$, are therefore "PGA-dominated", with the overturning fragility curve that approaches the rocking one, both in terms of median value and dispersion.

The influence of block dimensions on its behavior is also highlighted in the trend of median fragility curve values for the dimensionless IMs used by Dimitrakopoulos and Paraskeva (2015) (Fig. 13). Median $I M_{5}$ values tend to be constantly around 0.5 and there is negligible discrepancy among near and far field input motion for large $R$ values, which confirms that $I M_{5}$ may be a good generalized intensity measure for overturning in large rigid blocks. At small $R$ values, instead, median $I M_{5}=\frac{p P G V}{g \tan \alpha}$ deviates from 0.5 and there is a significant discrepancy among far field and near field, since the failure is "PGA-

Fig. 13 Median values of the overturning fragility curves for different dimensionless intensity measures

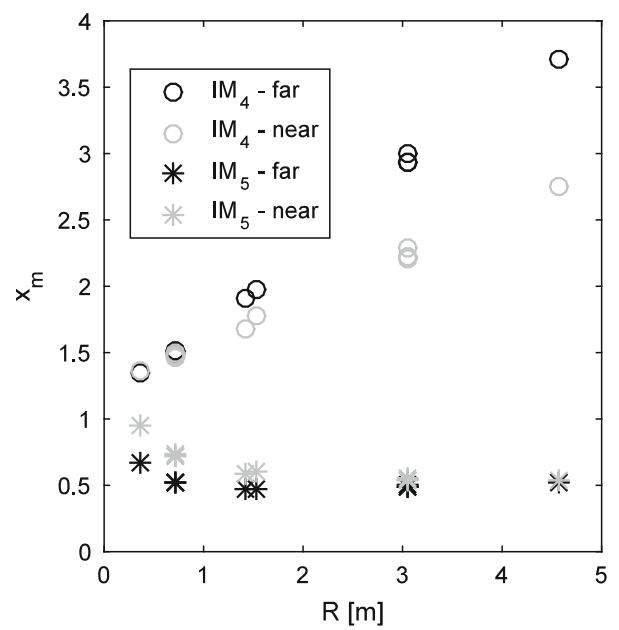


dominated". Interestingly, $I M_{4}=\frac{P G A}{g \tan \alpha}$ median values are not influenced by the nature of the input motion at small $\mathrm{R}$ values, which confirms that the PGA governs the overturning of small rigid blocks. $I M_{4}$ median values tend to assume value close to the ideal value of 1.0 as $\mathrm{R}$ becomes close to zero. It can be also demonstrated that $I M_{5}$ median value scales with $1 / \sqrt{R}$ for very small $R$ values if it is assumed that overturning occurs as soon as the block starts rocking, i.e. $I M_{4, \text { overt }}=I M_{4, \text { rock }} \cong 1.23$ (Fig. 14a). Under such an assumption the overturning $I M_{5}$ can be estimated as $I M_{5, \text { overt }} \cong \frac{1.23 p \cdot P G V}{P G A}$. Considering that $\frac{P G V}{P G A}$ is a feature of the selected accelerogram and it is not influenced by the block, it can be concluded that $I M_{5, \text { overt }} \propto p$ or, alternatively, $I M_{5, \text { overt }} \propto \sqrt{\frac{1}{R}}$. Moreover, $I M_{5}$ median value is proportional to $P G V / P G A$, justifying the discrepancies of the $I M_{5}$ median values for near- and far-field input motions at low $R$ values. It should be finally highlighted that the influence of block slenderness on overturning and rocking is not significant when dimensionless IMs are adopted.

The twenty fragility curves, i.e. for each rigid block subjected to one of the two input motion typologies, tend to overlap on a unique curve (Fig. 14) if expressed in terms of $I M_{4}=\frac{P G A}{g \tan \alpha}$ for rocking and $I M_{5}=\frac{p P G V}{g \tan \alpha}$ for overturning, respectively. The overlapping fragility curves for rocking with $I M_{4}$ suggest that the adopted dimensionless IM is an adequate candidate for generalized IM. The overturning fragility curves tend to overlap only for $R>1.0 \mathrm{~m}$, as anticipated above. A generalized IM is intended as an intensity measure which induces a unique fragility curve for all the rigid blocks regardless of their geometric properties. The definition of a generalized IM would be a powerful means in simplifying the assessment of seismic fragility of components behaving as rigid blocks.

A unique fragility curve can be therefore assessed, considering the numerical data of the ten considered rigid blocks subjected to both far field and near field input motions for rocking and only the blocks with $R>1.0 \mathrm{~m}$ for overturning. A generalization cannot be made for small rigid blocks. However, median overturning $P G A$ is not much larger than rocking $P G A$ for such blocks, i.e. less than $30 \%$ (Fig. 12b). As such, future investigations
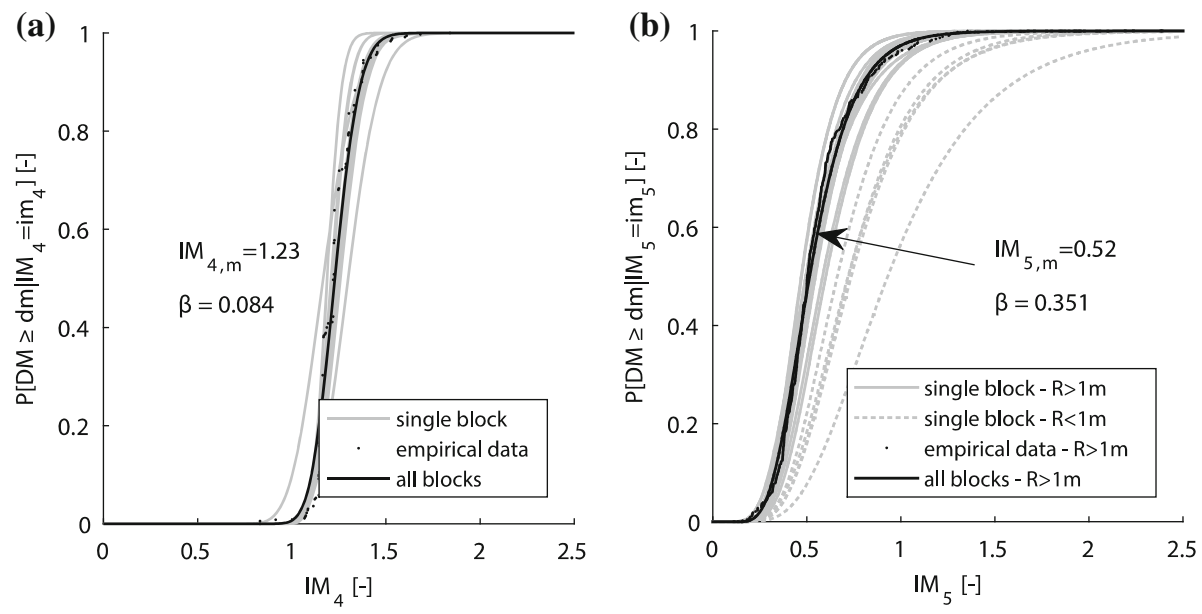

Fig. 14 Fragility curves considering ten different rigid blocks and both far and near input motions, for a rocking and $\mathbf{b}$ overturning, with dimensionless intensity measures 
might be focused on the definition of a generalized fragility curve for overturning of small rigid blocks by considering a PGA-based intensity measure.

It is therefore concluded that the curves in Fig. 14 can serve as a simple tool for the estimation of the damage occurred in rigid blocks after earthquakes. Moreover, they can be also included in performance-based design software for the estimation of the expected loss due to earthquake, for a rapid assessment of the damage occurred in non-structural components which behave as rigid blocks. The above mentioned results apply to a rigid block placed at a given story of a structure. They suggest that structural engineers should also control peak floor velocities in addition to peak floor accelerations, in order to assess the performance of freestanding rigid nonstructural components.

This preliminary analysis can be rigorously applied only to rigid blocks placed at the ground floor of buildings, due to the assumed set of accelerograms. Future studies will deal with the investigation of rigid blocks subjected to typical floor motions characterised by a frequency content which is significantly different than base motion content. Moreover, more refined modelling techniques, which take into account the interaction between elasticity and rigid block behavior (Acikgoz and DeJong 2012), will also be considered.

\section{Conclusions}

The paper deals with the assessment of the adequacy of existing numerical models in predicting the seismic response of freestanding nonstructural components and the assessment of their fragility. Based on a previous experimental campaign on hospital building contents, the study focuses on two different modeling techniques: (a) finite element method (FEM) and (b) rigid block model. The ability to predict the response of two tested hospital cabinets is verified by comparing the numerical response with the experimental one. The applicability and limitations of each modeling technique are also discussed. The fragility of several rigid blocks is numerically assessed to investigate the influence of their geometric properties on their performance.

The study first develops simple FEM models for the tested cabinets, subjecting them to the recorded table accelerations. A close numerical-to-experimental matching is observed for low-intensity shake table tests, when the cabinets are laterally deforming without any rocking mechanism. FEM models are not capable to reproduce the recorded accelerations at larger table accelerations, particularly due to the presence of some spikes in the recorded accelerograms, caused by the occurrence of rocking. It can be therefore concluded that the developed numerical model is efficient until the cabinet exhibits the rocking mechanism. The defined FEM models are also able to recognize the occurrence of the rocking mechanism, denoted by the occurrence of vertical tension displacements in the link at the base of the cabinets.

Acceleration pattern along the height of the cabinets is then assessed in order to predict the occurrence of possible rocking mechanisms and, therefore, assess whether FEM models are applicable. Moreover, it also allows assessing the acceleration demand on the contents, to protect them against sliding and/or overturning. The acceleration pattern is well matched by the structural horizontal acceleration profile along the building height provided by Eurocode 8, which provides a linear trend with top acceleration equal to 2.5 times the base acceleration. However, this outcome is limited to the specific tested components. For instance, a different component may exhibit a different damping ratio, resulting in different base-to-top acceleration amplification. 
Medical components, such as the tested cabinets, typically exhibit a rocking behavior as the seismic intensity increases. Thus, rigid block model becomes another good candidate to model the dynamic response of these components. Tested cabinets are modeled as equivalent rigid blocks and subjected to the experimental base accelerations. It is concluded that in case a 1.0 coefficient of restitution is considered, a slightly safe-sided estimation of the overturning PFA threshold can be performed. It is also shown that the rocking initiation is well predicted. It is therefore demonstrated that rigid block models can be employed in assessing the performance of hospital cabinets.

The question then arises as to which intensity measure (IM) is well correlated to the seismic performance of rigid blocks. A fragility study of rigid blocks is therefore conducted aimed to two different objectives: (a) assessment of the most efficient IM; (b) evaluation of the influence of geometric properties of the rigid block. Comprehensive incremental dynamic analyses on different rigid blocks highlight that the dimensionless intensity measure $P G A /(g \operatorname{tg} \alpha)$ is an efficient intensity measures to predict rocking occurrence in a generic rigid block. The intensity measure $p P G V /(g \operatorname{tg} \alpha)$ is the most efficient one only for large, say $R>2.0 \mathrm{~m}$, rigid blocks. Very small, say $R<1.0 \mathrm{~m}$, rigid blocks tend to overturn as soon as they start rocking and are therefore "PGA-dominated". $P G A /(g \operatorname{tg} \alpha)$ is therefore more efficient for such blocks. The use of these intensity measures allows assessing a unique fragility curve for rigid blocks characterized by different geometries, which may serve as a simple tool for the estimation of the damage occurred in rigid blocks after earthquakes.

Acknowledgements The research study presented in the present paper has been funded by the Italian Department of Civil Protection in the frame of the national DPC-ReLUIS 2015-2016, RS9 Health Care Facilities. The authors would like to acknowledge Siniat that provided the ceiling and the partitions used in the testing program. The insightful discussions with Prof. G. Maddaloni, who assisted with the full scale shaking-table tests, are fully appreciated. The support by Mr. D. D'Angela for the numerical simulations is also acknowledged.

Open Access This article is distributed under the terms of the Creative Commons Attribution 4.0 International License (http://creativecommons.org/licenses/by/4.0/), which permits unrestricted use, distribution, and reproduction in any medium, provided you give appropriate credit to the original author(s) and the source, provide a link to the Creative Commons license, and indicate if changes were made.

\section{References}

Acikgoz S, DeJong MJ (2012) The interaction of elasticity and rocking in flexible structures allowed to uplift. Earthq Eng Struct Dyn 41:2177-2194. doi:10.1002/eqe.2181

American Society of Civil Engineers (2010) ASCE/SEI 7-10: Minimum Design Loads for Buildings and Other Structures. Reston, Virginia, US

Applied Technology Council (2008) Quantification of building seismic performance factors. ATC 63. Redwood city, California

Arias A (1970) A measure of earthquake intensity. In: Hansen RJ (ed) Seismic design for nuclear power plants. The MIT Press, Cambridge, pp 438-483

Bruneau M et al (2003) A framework to quantitatively assess and enhance the seismic resilience of communities. Earthq Spectra 19:733-752. doi:10.1193/1.1623497

CEN (2004) Eurocode 8: design of structures for earthquake resistance-part 1: general rules, seismic actions and rules for buildings. EN 1998-1. Brussels, Belgium

Chen MC et al (2015) Full-scale structural and nonstructural building system performance during earthquakes: part I-specimen description, test protocol and structural response. Earthq Spectra 32:737-770

CSI Computer \& Structures Inc. (2004) SAP2000. Linear and nonlinear static and dynamic analysis of threedimensional structures, Computer \& Structures, Inc. Berkeley, California 
Cosenza E, Manfredi G (2000) Damage indices and damage measures. Prog Struct Mat Eng 2:50-59. doi:10. 1002/(SICI)1528-2716(200001/03)2:1<50:AID-PSE7>3.0.CO;2-S

Cosenza E, Di Sarno L, Maddaloni G, Magliulo G, Petrone C, Prota A (2014) Shake table tests for the seismic fragility evaluation of hospital rooms. Earthq Eng Struct Dyn 44:23-40. doi:10.1002/eqe.2456

De Biasio M, Grange S, Dufour F, Allain F, Petre-Lazar I (2015) Intensity measures for probabilistic assessment of non-structural components acceleration demand. Earthq Eng Struct Dyn 44:2261-2280. doi:10.1002/eqe. 2582

Di Sarno L, Yenidogan C, Erdik M (2013) Field evidence and numerical investigation of the Mw $=7.1$ October 23 Van, Tabanl1 and the Mw $>5.7$ November earthquakes of 2011. Bull Earthq Eng 11:313-346. doi:10.1007/s10518-012-9417-0

Di Sarno L, Petrone C, Magliulo G, Manfredi G (2015a) Dynamic properties of typical consultation room medical components. Eng Struct 100:442-454. doi:10.1016/j.engstruct.2015.06.036

Di Sarno L, Petrone C, Magliulo G, Manfredi G (2015b) Experimental seismic performance assessment of hospital building contents. In: 2nd conference on improving the seismic performance of existing buildings and other structures. San Francisco, CA, USA

Dimitrakopoulos E, DeJong M (2012) Overturning of retrofitted rocking structures under pulse-type excitations. J Eng Mech 138:963-972. doi:10.1061/(ASCE)EM.1943-7889.0000410

Dimitrakopoulos EG, Paraskeva TS (2015) Dimensionless fragility curves for rocking response to near-fault excitations. Earthq Eng Struct Dyn 44:2015-2033. doi:10.1002/eqe.2571

Dimitrakopoulos E, Kappos AJ, Makris N (2009) Dimensional analysis of yielding and pounding structures for records without distinct pulses. Soil Dyn Earthq Eng 29:1170-1180. doi:10.1016/j.soildyn.2009.02. 006

Donaire-Ávila J, Mollaioli F, Lucchini A, Benavent-Climent A (2015) Intensity measures for the seismic response prediction of mid-rise buildings with hysteretic dampers. Eng Struct 102:278-295. doi:10. 1016/j.engstruct.2015.08.023

Fajfar P, Vidic T, Fischinger M (1990) A measure of earthquake motion capacity to damage medium-period structures. Soil Dyn Earthq Eng 9:236-242. doi:10.1016/S0267-7261(05)80002-8

FEMA P-750 (2009) NEHRP recommended seismic provisions for new buildings and other structures. Washington, DC, USA

Housner G (1952) Spectrum intensity of strong motion earthquakes. In: Proceedings symposium on earthquake and blast effects on structures, Los Angeles, California, USA

Housner GW (1963) The behavior of inverted pendulum structures during earthquakes. Bull Seismol Soc Am 53:403-417

International Conference of Building Officials (ICBO) (2000) AC 156 acceptance criteria for the seismic qualification of nonstructural components. ICBO Evaluation Service Inc, Whittier, California, USA

Ishiyama Y (1982) Motions of rigid bodies and criteria for overturning by earthquake excitations. Earthq Eng Struct Dyn 10:635-650. doi:10.1002/eqe.4290100502

Jacques CC, McIntosh J, Giovinazzi S, Kirsch TD, Wilson T, Mitrani-Reiser J (2014) Resilience of the Canterbury hospital system to the 2011 Christchurch earthquake. Earthq Spectra 30:533-554. doi:10. 1193/032013EQS074M

Konstantinidis D, Makris N (2009) Experimental and analytical studies on the response of freestanding laboratory equipment to earthquake shaking. Earthq Eng Struct Dyn 38:827-848. doi:10.1002/Eqe.871

Konstantinidis D, Nikfar F (2015) Seismic response of sliding equipment and contents in base-isolated buildings subjected to broadband ground motions. Earthq Eng Struct Dyn 44:865-887. doi:10.1002/ eqe. 2490

Kuo K-C, Suzuki Y, Katsuragi S, Yao GC (2011) Shake table tests on clutter levels of typical medicine shelves and contents subjected to earthquakes. Earthq Eng Struct Dyn 40:1367-1386. doi:10.1002/eqe. 1094

Lin S-L, MacRae GA, Dhakal RP, Yeow TZ (2015) Building contents sliding demands in elastically responding structures. Eng Struct 86:182-191. doi:10.1016/j.engstruct.2015.01.004

Lopez Garcia D, Soong TT (2003) Sliding fragility of block-type non-structural components. Part 1: Unrestrained components. Earthq Eng Struct Dyn 32:111-129. doi:10.1002/Eqe.217

Luco N, Cornell CA (2007) Structure-specific scalar intensity measures for near-source and ordinary earthquake ground motions. Earthq Spectra 23:357-392. doi:10.1193/1.2723158

Makris N, Konstantinidis D (2003) The rocking spectrum and the limitations of practical design methodologies. Earthq Eng Struct Dyn 32:265-289. doi:10.1002/eqe.223

Makris N, Vassiliou M (2014) Are some top-heavy structures more stable? J Struct Eng 140:06014001. doi:10.1061/(ASCE)ST.1943-541X.0000933 
Masi A, Santarsiero G, Gallipoli M, Mucciarelli M, Manfredi V, Dusi A, Stabile T (2014) Performance of the health facilities during the 2012 Emilia (Italy) earthquake and analysis of the Mirandola hospital case study. Bull Earthq Eng 12:2419-2443. doi:10.1007/s10518-013-9518-4

Pantoli E et al (2015) Full-scale structural and nonstructural building system performance during earthquakes: part II-NCS damage states. Earthq Spectra 32:771-794

Porter K, Kennedy R, Bachman R (2007) Creating fragility functions for performance-based earthquake engineering. Earthq Spectra 23:471-489. doi:10.1193/1.2720892

Psycharis IN, Fragiadakis M, Stefanou I (2013) Seismic reliability assessment of classical columns subjected to near-fault ground motions. Earthq Eng Struct Dyn 42:2061-2079. doi:10.1002/eqe.2312

Shi Y, Kurata M, Nakashima M (2014) Disorder and damage of base-isolated medical facilities when subjected to near-fault and long-period ground motions. Earthq Eng Struct Dyn. doi:10.1002/eqe.2417

Shome N, Cornell CA (1999) Probabilistic seismic demand analysis of nonlinear structures, Reliability of Marine Structures Program Report No. RMS-35. Department of Civil and Environmental Engineering, Stanford University, California

The MathWorks Inc. (2015) MATLAB 8.5 Natick, MA

World Health Organization (WHO) (2008) WHO/UNISDR World Disaster Reduction Campaign. http:// www.safehospitals.info/

Yim C-S, Chopra AK, Penzien J (1980) Rocking response of rigid blocks to earthquakes. Earthq Eng Struct Dyn 8:565-587. doi:10.1002/eqe.4290080606

Zhang J, Makris N (2001) Rocking response of free-standing blocks under cycloidal pulses. J Eng Mech 127:473-483. doi:10.1061/(ASCE)0733-9399(2001)127:5(473) 